\title{
Breast Cancer Incidence Reduction in Women Treated with Subcutaneous Testosterone: Testosterone Therapy and Breast Cancer Incidence Study
}

\author{
(1) Gary Donovitz ${ }^{1,2}$, (1) Mandy Cotten ${ }^{3}$ \\ ${ }^{1}$ Morehouse College of Medicine, Atlanta, Georgia, USA \\ ${ }^{2}$ BioTE Medical, LLC, Irving, Texas, USA \\ ${ }^{3}$ Institute for Hormonal Balance, Arlington, Texas, USA
}

\begin{abstract}
Objective: Testosterone (T) therapy has been shown to be breast protective in both pre- and post-menopausal patients. Additionally, estradiol (E) does not cause breast cancer (BC) in the majority of the world's literatures. This study aimed to investigate the incidence of invasive BC (IBC) in pre- and postmenopausal women treated with $\mathrm{T}$ therapy and $\mathrm{T}$ in combination with $\mathrm{E}(\mathrm{T} / \mathrm{E})$.

Materials and Methods: Since January 2010, a total of 2,377 pre- and post-menopausal women were treated with T or T/E implants. IBC rates were reported based on newly diagnosed IBC cases in the total study. Total cases divided by the total sample size and years in study was expressed as an incidence per 100,000 person-years (P-Ys). The BC incidence was compared with age-specific Surveillance Epidemiology and End Results (SEER) incidence rates.

Results: As of October 2020, 14 cases diagnosed with IBC have been found in 9,746 P-Y of follow up for an incidence of 144 cases per 100,000 P-Y, substantially less than the age-specific SEER incidence rates $(223 / 100,000)$, placebo arm of Women's Health Initiative Study $(330 / 100,000)$, and never users of hormone therapy from the Million Women Study $(312 / 100,000)$.

Conclusion: $\mathrm{T}$ and/or T/E pellet implants significantly reduced the incidence of $\mathrm{BC}$ in pre- and post-menopausal women. The addition of $\mathrm{E}$ did not increase the incidence over using $\mathrm{T}$ alone. This is the second multi-year long-term study demonstrating the benefits of $\mathrm{T}$ therapy in reducing the incidence of IBC.
\end{abstract}

Keywords: Pellet, testosterone pellet implantation, estradiol, breast cancer risk, hormone replacement therapy

Cite this article as: Donovitz G, Cotten M. Breast Cancer Incidence Reduction in Women Treated with Subcutaneous Testosterone: Testosterone Therapy and Breast Cancer Incidence Study. Eur J Breast Health 2021; 17(2): 150-156

\section{Key Points}

- In the United States, 240,000 women will develop breast cancer (BC) annually and 40,000 will die from the disease.

- Testosterone hormone optimization has been shown to reduce the incidence of invasive breast cancer in women.

- This study (The Testosterone Therapy and Breast Cancer Incidence Study) is the largest long term study to further demonstrate this benefit and shows a reduced incidence of IBC in women taking testosterone and estradiol sub-cutaneous hormone pellet therapy.

\section{Introduction}

Hormone replacement therapy (HRT) is a type of treatment that involves taking hormones to prevent or treat certain medical conditions and/ or symptoms associated with female menopause and pre-menopause. These symptoms can include hot flashes, insomnia, vaginal atrophy, accelerated skin aging, vaginal dryness, decreased muscle mass, sexual dysfunction, night sweats, fatigue, joint pain, and others. These symptoms are in large part related to diminished levels of sex hormones. Improvement of symptoms is achieved through hormone replacement and optimization. Furthermore, long-term benefits of HRT include reduced risk for bones, heart, brain, and different cancers (1-3).

In the United States, 240,000 women developed breast cancer (BC) annually and 40,000 will die from the disease (4). The lifetime risk of developing $\mathrm{BC}$ is 1 in 8 (5). HRT for menopause women has been used mostly in western countries, with about 600 million woman-years of use since 1970 . 
Some articles have shown excess $\mathrm{BC}$ risks, with duration of use that were greater for estrogen-progestogen (EPT) than estrogen (ET) only preparations $(6,7)$. In contrast, the Women's Health Initiative (WHI), the largest long-term randomized clinical trial of combined equine ET alone (CEE alone) or EPT, found a significantly higher risk of developing invasive $\mathrm{BC}$ (IBC) among women using EPT, whereas a lower risk was observed in CEE alone arm (8). Others have shown a reduction in BC risk (9). Variations and differences in outcomes may be due to heterogeneity in studies including but not limited to Body Mass Index (BMI), age at onset of HRT, hysterectomy status, bio-identical versus synthetic hormone formulations, and route of administration (oral vs non-oral). Adding to the conundrum, the risk associated with EPT differed according to the progestin used, resulting in higher risk with medroxyprogesterone acetate, levonorgestrel, and norethisterone [odds ratio (OR): 1.87, confidence interval (CI): 1.71-2.05; OR: 1.79, CI: 1.68-1.90; and OR: 1.88, CI: 1.79-1.99, respectively] and lower with dydrogesterone (OR: 1.24, CI: 1.031.48) after 5 years of therapy (10).

Excess risk associated with EPT duration was seen across all and hormone receptor subtypes. In addition, duration of EPT use was linked to excess overall BC risk and to ductal (DCIS) and lobular cancer in situ (LCIS). For ET users, no statistically significant differences were seen for either DCIS or LCIS (7).

Certain types of ET showed to stimulate breast tissue and increase the risk of BC. Prior to the current study, only one long-term study was published on the benefits of testosterone (T) therapy in women (9). The risk of developing BC showed to be increased by elevated endogenous ET levels (11). Androgens showed to counteract the proliferative effects of ET in mammary tissue (12). Breast tissue extirpated from pre- and post-menopausal women also has demonstrated the inhibitory effects of $\mathrm{T}$ on breast cell proliferation $(13,14)$. The corollary has also been reported that bio-available $\mathrm{T}$ is significantly lower in women with $\mathrm{BC}$, which supports the protective role that hormone optimization with $\mathrm{T}$ affords to patients (15). Adherence to $\mathrm{T}$ hormone pellet therapy has furthermore shown to reduce the incidence of $\mathrm{BC}$ from 330 per 100,000 women years (placebo arm of the WHI) to 165 per 100,000 women years in the Dayton study in patients using $\mathrm{T}$ and/or $\mathrm{T}$ with anastrozole subcutaneous hormone pellet therapy (9).

T therapy has been increasing $12 \times$ worldwide since year 2000 . Benefits to the bones, heart, and brain have been reported (1-3). The current study is a retrospective observational study that was specifically designed to investigate the incidence of $\mathrm{BC}$ in women treated with subcutaneous $\mathrm{T}$ and/or $\mathrm{T} / \mathrm{E}$ implants for clinical syndrome of $\mathrm{T}$ deficiency and/or menopausal state.

\section{Materials and Methods}

\section{Study design, setting, and participants}

All data analyzed was drawn from patients at the Institute for Hormonal Balance (IHB) as part of an Institutional Review Board (IRB) exempt study that retrospectively investigated the incidence of $\mathrm{BC}$ in women treated with subcutaneous $\mathrm{T}$ or $\mathrm{T} / \mathrm{E}$ implants from January 2010 to 2020 .

Data for analysis was identified based on presentation to the clinic with symptoms of $\mathrm{T}$ and/or ET deficiency including hot flashes, night sweats, insomnia, depressive mood, irritability, anxiety, fatigue, memory loss, menstrual or migraine headaches, vaginal dryness, reduced libido, and urinary symptoms including incontinence, muscle pain, and/or bone loss (5). Both pre- and post-menopausal patients were considered for retrospective analysis. Estradiol (E) implants were utilized if laboratory testing indicated necessity for E2 administration (follicle-stimulating hormone $(\mathrm{FSH})>23$ and last menstrual period (LMP) $>6$ months prior). $\mathrm{T}$ administration was offered if clinical symptoms for $\mathrm{T}$ deficiency were present and laboratory testing confirmed a serum level of $<70 \mathrm{ng} / \mathrm{dl}$. All female patients opting to receive human identical hormone pellet therapy as their method for replacement were considered for analysis in this study. If patients were post-menopausal, defined as FSH $>23$ and no longer menstruating, requiring $\mathrm{E}$ subcutaneous pellets with or without oral micronized progesterone based on hysterectomy status, their data was included from the study. Women with a personal history of BC were excluded from data analysis. No patient was excluded from analysis based on age, prior hormone use, oral contraceptive use, endometrial pathology, breast density, BC family history, menopausal status, or BMI. Mammography and clinical breast exam were not protocol determined. Screening mammograms were not required for data from a patient to be considered for analysis. Patients who had received T implants prior to the IRB exemption date were also not excluded from analysis. Study size was therefore not predetermined. The incidence of $\mathrm{BC}$ in our study population was to be compared to historical controls (e.g., placebo control group of WHI combined arm) (8), as well as age-specific Surveillance Epidemiology and End Results (SEER) data. The SEER data is from www.seer.cancer.gov and is an authoritative source for cancer statistics in the United States. It is notable that SEER data for IBC in women age 40-64 years has changed very little over the past 17 years (16).

\section{Subcutaneous implants, the evolution of $\mathrm{T}$ therapy in clinical prac- tice, and $T$ with and without $E$ implants}

The $\mathrm{T}$ and $\mathrm{E}$ implants used at the Institute for Hormone Balance and its satellite offices are compounded by a 503b outsourcing pharmacy in Denton, Texas. They are composed of USP $\mathrm{T}$ and steric acid or USP E and steric acid (5.21\%). A proprietary Food and Drug Administration (FDA) approved process compresses substrates into 3.1 $\mathrm{mm}$ (diameter) cylinders, sealed in glass ampoules, and sterilized by $\mathrm{E}$ beam sterilization. Sterile implants are inserted into the subcutaneous tissue of the upper gluteal area or lower abdomen through a small anesthetized incision using a stainless-steel sterile trocar or a disposable trocar kit.

The IHB has been involved in bio-identical HRT over the past 24 years. Oral ET therapy and ET and/or T creams were used in majority of patients needing replacement through 2007. The practice augmented our armamentarium of HRT adding the use of subcutaneous hormone pellet therapy in 2008. From our experience, subcutaneous hormone pellet therapy provides improved relief of symptoms with fewer side effects than more traditional HRT therapies. The success of $\mathrm{T}$ implants in treating symptoms of pre- and post- menopausal patients was additionally shown by Glaser et al (17). The IHB developed a proprietary dosing computerized algorithm for pellet dosing based on patient demographics, symptoms, laboratory values, and medical comorbidities.

\section{Data analytics and patient follow up}

From January 2010 through October of 2020, data from the Testosterone Therapy and Breast Cancer Incidence Study was entered into a secure, custom tracking App, using Microsoft Azure App Services and MS SQL Database integrated with a proprietary dosing site and 
industry leading Pharmacy Dispensing software (BioTracker ${ }^{\odot}$ ). Patient data was also entered into an electronic medical record program with all history, laboratory data, and pellet insertion dosage, including start and end dates. Most patients returned for subsequent insertion at 90-120 days based on symptom return. Follow-up calls and serum lab testing were performed at 4-6 weeks after first insertion and then annually. Patients were evaluated at each visit and T and ET dosing was adjusted based on clinical symptom improvement and secondary responses reported. All patients no longer receiving therapy or those on therapy agreed to contact the office for any subsequent diagnosis of BC. All patients were contacted if they did not return for pellet therapy after 365 days. This served as an end date, and person-year (P-Y) would no longer accrue. They were screened for BC and any side effects arising from pellet therapy and reminded to report any IBC diagnosis in the future. In year 9, all patients underwent chart reviews to evaluate subsequent diagnosis of IBC. All patients who discontinued therapy at some point during the study ( $78 \%$ of the total enrolled) were contacted 1 year from their last insertion. The practice, in addition, performed follow up after obtaining suspicious mammogram results and surgical pathology reports to confirm the diagnosis and type of IBC.

\section{Statistical analysis}

$\mathrm{BC}$ rates are reported as number of newly diagnosed cases (unadjusted and un-weighted) divided by the total P-Ys of "at risk" population under observation. P-Ys of observation for each participant was calculated from the date of first $\mathrm{T}$ pellet insertion for the participant up to the date of cancer detection or therapy end date (1 year for those who discontinued therapy or latest contact date for those still under therapy), whichever came first and dividing that by 365 . The program logic accurately and continually tracks the number of P-Ys based on the above logic for each participant and calculates a running sum (cumulative total) across the group.

To evaluate adherence rates, data submitted through BioTracker ${ }^{\oplus}$ was used to calculate the adherence rate of pellet use among participants over the study duration. The continuation rate is defined as the incidence of patient undergoing an implant procedure to have a subsequent implant procedure within 12 months of the initial procedure. BioTracker ${ }^{\oplus}$ preserved the database for retrospective analysis.

The incidence of BC was calculated per 100,000 p-y so that our results could be compared to the incidence of $\mathrm{BC}$ in published historical controls, as done in other studies as well as published $\mathrm{BC}$ incidence rates $(8,9,15,16,18)$ (Table 1$)$.

Utilizing SEER incidence rates, the expected BC incidence rate for our intent-to-treat group was calculated from the age distribution of enrolled patients (Graph 1). IBC rates from the Testosterone Health Initiative were compared to the age-adjusted SEER BC incidence rates published over nearly the same time frame.

\section{Results}

\section{Patient demographics}

As of December 2013, a total of 2,377 patients were identified as part of our retrospective analysis. This data showed that $19 \%$ of patients discontinued pellet therapy after the initial pellet insertion. Specific reasons for discontinuation after the initial pellet insertion were not captured as part of the data acquisition.

Table 1. Breast cancer cases in women using testosterone (T) or T with estradiol (T/E) compared with major studies using estrogen (ET), progestin (P) therapy, E/P/T/, E/T, past users, never users, and SEER incidence rates

\begin{tabular}{|c|c|c|c|}
\hline Study & $\begin{array}{c}\text { Number of the } \\
\text { Patients }\end{array}$ & $\begin{array}{c}\text { Cases } \\
\text { per } 100,000 \text { p-y }\end{array}$ & Years observed \\
\hline \multicolumn{4}{|c|}{ The Testosterone Therapy and Breast Cancer Incidence Study (current study) } \\
\hline $\mathrm{T}, \mathrm{T}+\mathrm{E}$ & 2,377 & 144 & 9 \\
\hline \multicolumn{4}{|c|}{ Dayton Study (5) } \\
\hline $\mathrm{T}, \mathrm{T}+\mathrm{Al}$ & 1,267 & 165 & 10 \\
\hline \multicolumn{4}{|l|}{ WHI, RCT (8) } \\
\hline Placebo & 8,102 & 330 & 10.7 \\
\hline E alone & 10,000 & 260 & 10.7 \\
\hline$E+P$ & 8,506 & 380 & 5.2 \\
\hline \multicolumn{4}{|l|}{ MWS (16) } \\
\hline Never users & 513,272 & 312 & 14 \\
\hline E alone, $E+P$ & 394,697 & 501 & 14 \\
\hline \multicolumn{4}{|l|}{ Adelaide (13) } \\
\hline$T+E$ & 161 & 115 & 5.9 \\
\hline$T+E+P$ & 347 & 293 & 5.9 \\
\hline SEER (14) & & 223 & - \\
\hline
\end{tabular}

Al: Anastrozole; WHI: Women's Health Initiative; RCT: Randomized controlled trial; MWS: Million Women Study; SEER: Surveillance Epidemiology and End Results 
In the $\mathrm{T}$ arm, 640 women received more than one round of $\mathrm{T}$ pellet therapy and were therefore eligible for analysis. In addition, 1,737 patients received $\mathrm{T}$ and $\mathrm{E}$ pellet therapy for more than one round and were eligible for analysis (Chart 1).

The majority of patientswhich is $>90 \%$ were accrued into the study by year 4 . The mean number of years since first $T$ implant was 8.8 years (range: $4.1-12.7)$. The youngest patient was 29 years old and the oldest was 87 years old (range: $29-87$ years).

In Table 2, patient demographics are listed at the time of entry to the Testosterone Therapy and Breast Cancer Incidence Study. Our population was drawn from a group of long-term older gynecologic

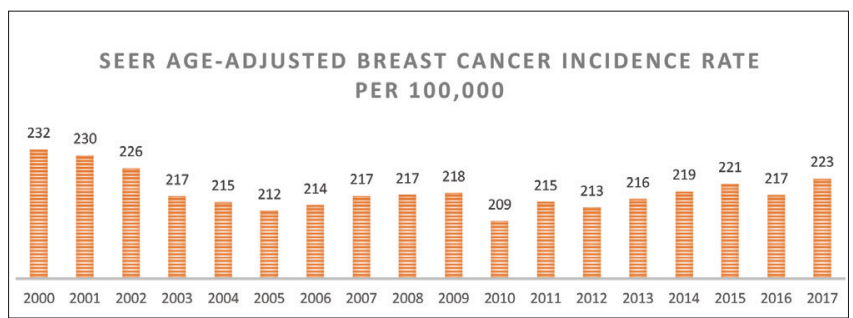

Graph 1. Breast cancer recent trends in SEER age-adjusted incidence rates, 2000-2017

All races (including Hispanic), ages: 40-64, all stages, delay-adjusted rates SEER: Surveillance Epidemiology and End Results

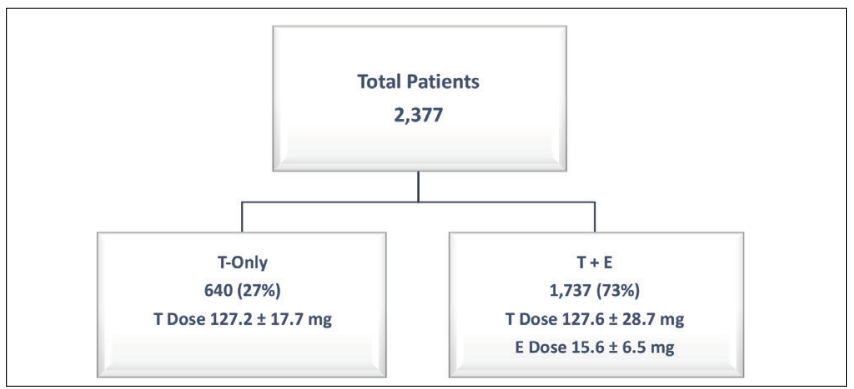

Chart 1. Accrued Patients for analysis and dosing comparison

T: Testosterone; E: Estradiol

Table 2. Patient demographics

\section{Patient demographics}

Participants accrued (n)

Eligible for analysis, ITT

2,377

Completed only 1 round of pellets

Age at first implant, year

ITT

Completed only 1 round of pellets

$56.7 \pm 8.3$

Menopausal (\%)

Surgical (\%)

Natural (\%)

Pre/perimenopausal (\%)

23.2

Family history of breast cancer (\%)

28

BMI $\left(\mathrm{kg} / \mathrm{m}^{2}\right)$

$27.2 \pm 5.3$

ITT: Intent-to-treat; BMI: Body mass index; n: Number

patients from the local population of the four IHB sites from which data were drawn from analysis as summarized in Table 2 . The group was neither at an increase or decrease risk of IBC based on demographics. The mean age at first $T$ pellet insertion was $58.7 \pm 8.0$ years. $76 \%$ of patients were menopausal, with $2 / 3$ of them having their uterus extirpated; $23 \%$ were pre/perimenopausal; and $28 \%$ had a positive family history of BC.

\section{$\mathrm{BC}$ incidence}

As of October 2020, 14 IBC cases were diagnosed out of the 2,377 women in the use Testosterone Therapy and Breast Cancer Incidence Study (Table 3). These women all received more than two rounds of T implant therapy. This calculation based on P-Y of therapy adjusted to 100,000 P-Y of therapy resulted in an incidence of 144/100,000 P-Y.

\section{Testosterone Therapy and Breast Cancer Incidence Study vs SEER and historical controls}

A marked reduction in IBC cases was found in our accrued study group compared to the age matched SEER expected number of BC cases (14 vs 48 cases). The incidence rate for Testosterone Therapy and Breast Cancer Incidence Study was $144 / 100,000$ vs 223/100,000 for the SEER data. Alternatively, one could compare our data to the placebo arm of WHI. Doing so, a marked reduction is observed in IBC cases in our accrued study group. We again accrued 14 cases of IBC vs 71 expected from the placebo arm of WHI. The incidence rate for Testosterone Therapy and Breast Cancer Incidence Study was $144 / 100,000$ vs 330/100,000 for the WHI placebo patient arm (Table 1).

\section{Characteristics of IBC study group (Table 3)}

A total of 14 patients with reported and diagnosed IBC are presented in Table 3. All tumors were identified with mammography. The mean age at first $T$ Therapy was $54.3 \pm 7.4$ years. The mean age at diagnosis was $59.0 \pm 6.2$ years. The mean length of therapy prior to diagnosis was 4.6 years (range: $1.2-10.5$ years). Three of 14 patients with IBC had history of smoking; 12 of 14 IBC were DCIS and two were LCIS; and 13 of $14 \mathrm{BCs}$ were $\mathrm{ER}+/ \mathrm{PR}+$.

\section{Discussion and Conclusion}

Testosterone Therapy and Breast Cancer Incidence Study, a 9-year retrospective study, demonstrated a $35.5 \%$ reduction in IBC in both T and T/E hormone pellet implant users compared to age-specific SEER incidence rates $(223 / 100,000)$. This study was done in nearly parallel fashion with the Dayton study using $\mathrm{T}$ and/or T/Anastrozole pellets (9). The Dayton experience also resulted in a significant lowered incidence of IBC in T implant users.

Subcutaneous $\mathrm{T}$ implants have been used to treat $\mathrm{T}$ deficiency in women since 1937 (19, 20). Additionally, T implants have been used to treat IBC (21). T is increasingly recognized as a vital hormone in women. In 2018, an International Consensus Group met regarding the use of $\mathrm{T}$ in women and unanimously agreed that $\mathrm{T}$ was the most important hormone for women regardless of the decade of life (22). By age 40 , women have reduced their production of $\mathrm{T}$ by $50 \%$ and mostly are $\mathrm{T}$ deficient (23).

$\mathrm{T}$ promotes downstream physiological processes via functional androgen receptors (ARs) that are located in almost all tissues, including the breast, heart, blood vessels, gastrointestinal tract, brain, bladder, uterus, vagina, ovaries, skin, bone, bone marrow, muscle, 
Table 3. Patient data diagnosed with invasive breast cancer for the duration of the study

\begin{tabular}{|c|c|c|c|c|c|c|c|c|c|}
\hline Patient & $\begin{array}{l}\text { Age at } 1 \text { st } \\
\text { TTY }\end{array}$ & BMI & Smoker & FH IBC & Detection & Hysterectomy & $\begin{array}{l}\text { IBC } \\
\text { type }\end{array}$ & $\begin{array}{l}\text { Date of } \\
\text { diagnosis }\end{array}$ & $\begin{array}{l}\text { Receptor } \\
\text { status }\end{array}$ \\
\hline 1 & 50.4 & 26.0 & $\mathrm{Y}$ & $\mathrm{Y}$ & Mammo & No & $\begin{array}{l}\text { Invasive ductal } \\
\text { carcinoma }\end{array}$ & $1 / 15 / 2020$ & $\mathrm{ER}+/ \mathrm{PR}+$ \\
\hline 2 & 45.9 & 26.2 & $\mathrm{~N}$ & $\mathrm{~N}$ & Mammo & No & $\begin{array}{l}\text { Invasive ductal } \\
\text { carcinoma }\end{array}$ & $6 / 3 / 2019$ & $\mathrm{ER}+/ \mathrm{PR}+$ \\
\hline 3 & 50.4 & 26.0 & $\mathrm{~N}$ & $Y$ & Mammo & No & $\begin{array}{l}\text { Invasive ductal } \\
\text { carcinoma }\end{array}$ & $1 / 3 / 2016$ & $\mathrm{ER}+/ \mathrm{PR}+$ \\
\hline 4 & 41.0 & 19.9 & $\mathrm{~N}$ & $\mathrm{~N}$ & Mammo & Yes & $\begin{array}{l}\text { Invasive lobular } \\
\text { carcinoma }\end{array}$ & $10 / 18 / 2018$ & $\mathrm{ER}+/ \mathrm{PR}+$ \\
\hline 5 & 51.4 & 45.4 & $\mathrm{~N}$ & $\mathrm{~N}$ & Mammo & No & $\begin{array}{l}\text { Invasive lobular } \\
\text { carcinoma }\end{array}$ & $8 / 1 / 2018$ & $\mathrm{ER}+/ \mathrm{PR}+$ \\
\hline 6 & 53.8 & 23.9 & $\mathrm{~N}$ & $\mathrm{~N}$ & Mammo & Yes & $\begin{array}{l}\text { Invasive ductal } \\
\text { carcinoma }\end{array}$ & $7 / 15 / 2019$ & $\mathrm{ER}+/ \mathrm{PR}+$ \\
\hline 7 & 59.8 & 29.9 & $\mathrm{~N}$ & $\mathrm{Y}$ & Mammo & Yes & $\begin{array}{l}\text { Invasive ductal } \\
\text { carcinoma }\end{array}$ & $2 / 3 / 2017$ & $\mathrm{ER}+/ \mathrm{PR}+$ \\
\hline 8 & 49.7 & 26.9 & $\mathrm{Y}$ & $\mathrm{Y}$ & Mammo & Yes & $\begin{array}{l}\text { Invasive ductal } \\
\text { carcinoma }\end{array}$ & $7 / 6 / 2018$ & $\mathrm{ER}+/ \mathrm{PR}+$ \\
\hline 9 & 70.8 & 22.9 & $\mathrm{~N}$ & $\mathrm{~N}$ & Mammo & No & $\begin{array}{l}\text { Invasive ductal } \\
\text { carcinoma }\end{array}$ & $8 / 14 / 2013$ & ER-/PR- \\
\hline 10 & 44.3 & 20.6 & $\mathrm{~N}$ & $\mathrm{~N}$ & Mammo & No & $\begin{array}{l}\text { Invasive ductal } \\
\text { carcinoma }\end{array}$ & $9 / 27 / 2018$ & $\mathrm{ER}+/ \mathrm{PR}+$ \\
\hline 11 & 52.3 & 27.0 & $\mathrm{~N}$ & $\mathrm{~N}$ & Mammo & No & $\begin{array}{l}\text { Invasive ductal } \\
\text { carcinoma }\end{array}$ & $10 / 10 / 2018$ & $\mathrm{ER}+/ \mathrm{PR}+$ \\
\hline 12 & 57.0 & 25.8 & $\mathrm{~N}$ & $\mathrm{Y}$ & Mammo & No & $\begin{array}{l}\text { Invasive ductal } \\
\text { carcinoma }\end{array}$ & $9 / 20 / 2014$ & $\mathrm{ER}+/ \mathrm{PR}+$ \\
\hline 13 & 59.0 & 31.0 & $\mathrm{~N}$ & $\mathrm{Y}$ & Mammo & Yes & $\begin{array}{l}\text { Invasive ductal } \\
\text { carcinoma }\end{array}$ & $10 / 20 / 2012$ & $\mathrm{ER}+/ \mathrm{PR}+$ \\
\hline 14 & 58.6 & 33.2 & $\mathrm{Y}$ & $\mathrm{N}$ & Mammo & No & $\begin{array}{l}\text { Invasive ductal } \\
\text { carcinoma }\end{array}$ & $3 / 7 / 2014$ & $\mathrm{ER}+/ \mathrm{PR}+$ \\
\hline
\end{tabular}

FH: Family history; IBC: Invasive breast cancer; Y: Yes; N: No; BMI: Body mass index; ER: Estrogen receptor; PR: Progesterone receptor; TTY: Testosterone Therapy, year

joints, and adipose tissue. Use of the validated Menopause Rating Scale questionnaire has yielded objective evidence that $\mathrm{T}$ treatment significantly reduces symptoms in pre- and post-menopausal women (17).

In order to reduce cardiovascular disease, Alzheimer's disease, osteoporosis, and certain types of cancer (e.g., BC), a safe and effective route of administration for $\mathrm{T}$ is needed (20). Clinical studies in primates, in vitro evidence suggest that $T$ androgen receptor complex (T-AR) is anti-proliferative that counteracts the stimulatory effects of ET (12). In addition, studies have shown in humans that T-AR downregulates the ER $\alpha$ receptor, is antiproliferative, and increases apoptosis of BC cell lines (3, 24). In 2014, neoadjuvant hormone therapy utilizing $\mathrm{T}$ implants demonstrated a significant clinical response rapidly decreasing the volume of an IBC followed by ultrasound surveillance (21).

At this time, no other route of delivery for $\mathrm{T}$ has demonstrated a transdermal routes of administration were short in duration and failed to show the benefits seen with subcutaneous $\mathrm{T}$ hormone pellet therapy (25). The physiology of T implants allows more consistent steady state serum levels compared to other modalities, and as such the benefits in reducing IBC may not extend to oral or transdermal $\mathrm{T}$ delivery methods. The controversy over serum levels of $\mathrm{T}$ in the Dayton study and ours should be laid to rest at this point. In 2002, the Princeton Group published their findings that normal T levels for women are not established (26). Glaser and Dimitrakakis (24) published data with the rationale and efficacy of higher peak serum levels and safety of these levels in women. It has been established that T deficiency in women is a clinical syndrome and the inter-patient variability to resolve symptoms is basically inconsequential (20). Most recently, current authors have submitted for publication a 7-year study titled Low Complication Rates of T and E Implants for androgen and ET Replacement Therapy (ERT) in over one million procedures. Complications in women were $<1 \%$ even though the peak serum levels were often in the lower range of normal for endogenous $\mathrm{T}$ in males (Under review). 
A major strength of this study is that pellet therapy has an extremely high continuation rate, $>81 \%(27)$. As such, the ability to evaluate patients at each office visit allows for improved maintenance of reinsertion intervals and improved screening for mammogram compliance. It also allowed for tracking any changes in medical diagnoses and/or adverse events. Additional strength of this study is the large sample size, in fact the largest reported on IBC prevention in the world literature. The single practice sample pool and limited number of practitioners allowed for consistency in therapy, record keeping, and tracking of adverse events.

A major limitation of this study is the self-reporting of patients that could lead to a selection bias and underreporting. There are several minor limitations of this study. The co-administration of $\mathrm{E}$ could have led to an increase in IBC theoretically; however, this was not the case in Adelaide's study (15), nor this one. The controversy surrounding $\mathrm{E}$ as a causative agent in BC persists nearly 20 years after WHI. It is beyond the scope of this paper to elaborate about all studies, but the argument on both sides is well expanded upon in Avrum Bluming MD book entitled Estrogen Matters (28). We know that no increase was found in BC in the ERT arm of WHI (8) as well as in BC with ET alone in the Million Women Study (18), and in BC in the Nurses' Health study in women on ERT (25). In addition, no increase was found in cancer mortality after 16 years of follow up after WHI (29). Studies showed the efficacy of ET therapy in treating BC (30). The use of progesterone in women receiving $\mathrm{E}$ who had maintained their uterus could have theoretically contributed to the lower incidence of IBC (3). Benefits of progesterone/progestins in $\mathrm{ER}+/ \mathrm{PR}+$ tumors remain controversial (31).

A final limitation of this study is the lack of a matched control group in the study design. This study, similar to the Dayton study, was set up as a "real world" study of women who met the clinical criteria for $\mathrm{T}$ deficiency. It was not set up as a controlled pharmaceutical trial. Finally, some may consider a limitation of this study the lack of control for aromatization. The individual and potential synergistic effects of anastrozole with $\mathrm{T}$ remain controversial and unknown. Our data was generated and accrued prior to the Dayton experience.

Our 9-year data supports the clinical studies in the literature supporting protective effects of $\mathrm{T}$ administration in pre- and postmenopausal women reducing the incidence of BC. Other benefits related to symptom relief of $\mathrm{T}$ deficiency have been reported over the past 80 years. Hundreds of thousands of women have seen an improvement in their general health and quality of life by optimizing their hormones. At this point, no FDA approved human identical T is commercially available for women. Our safety data (under review) and this large "real world" observational study hopefully will narrow the gender gap regarding approval of $\mathrm{T}$ implant formulations for women.

The Testosterone Therapy and Breast Cancer Incidence Study, a 9-year retrospective study, demonstrated a $35.5 \%$ reduction in IBC compared to the age matched SEER expected incidence. The large sample size and length of this trial make it one of the most significant studies on this subject reported to date. Age of patients and other demographic data represents a normal population for study in a general Ob-Gyn practice with neither excess nor diminished risk for IBC. This is the second long-term study in women evaluating the protective effect $\mathrm{T}$ subcutaneous hormone implants for IBC.
We should remain cognizant that hormone preparations have changed over the years. Route of delivery matters in assessing risk and side effects. That association does not equal causation. Evidence-based medicine provides the best research evidence and clinical knowledge to assess and treat clinical syndrome and symptoms of the menopause. Finally, improving quality of life in menopausal patients often involves shared decision-making with our patients (32).

\section{Acknowledgements}

The authors would like to thank Priscilla Long and Tammy White for their tireless work in maintaining datasets. Amit Jain was invaluable in assisting with the statistical analysis and organization of the database.

Ethics Committee Approval: This retrospective study was performed with an IRB exemption, Integreview Protocol \# 002 (Donovitz).

Informed Consent: Retrospective study.

Peer-review: Externally peer-reviewed.

\section{Authorship Contributions}

G.D. designed the study. Both M.C. and G.D. administered all of the hormone pellet therapy. Both authors contributed to the writing of the manuscript and approved the final manuscript.

Conflict of Interest and Financial Disclosure: G.D. is the Founder, Chairman, and Chief Medical Officer of BioTE Medical, L.L.C. a training and marketing company for instruction in various HRT modalities. M.C. is the owner of the Institute for Hormonal Balance.

\section{References}

1. Studd J, M Savvas, N Waston, Garnett T, Fogelman I, Cooper D. The relationship between plasma estradiol and the increase in bone density in postmenopausal women after treatment with subcutaneous hormone implants. Am J Obstet Gynecol 1990; 163: 1474-1479. (PMID: 2240090) [CrossRef]

2. Iellamo F, Volterrani M, Caminiti G, Karam R, Massaro R, Fini M, et al. Testosterone therapy in women with chronic heart failure: a pilot doubleblind, randomized, placebo-controlled study. J Am Coll Cardiol 2010; 56: 1310-1316. (PMID: 20888520) [CrossRef]

3. Friedman E. How you and your doctor can fight breast cancer, prostate cancer, and alzheimer's. New York: Prometheus; 2013. [CrossRef]

4. National Cancer Institute (2018). Breast cancer treatment. Available from; https://www.cancer.gov/types/breast/hp/breast-treatment-pdq [CrossRef]

5. Glaser RL, York AE, Dimitrakakis C. Incidence of breast cancer in women treated with testosterone implants: a prospective 10-year cohort study. BMC Cancer 2019; 19: 1271. (PMID: 31888528) [CrossRef]

6. Collaborative Group on Hormonal Factors in Breast Cancer. Type and timing of menopausal hormone therapy and breast cancer risk: individual participant meta-analysis of the worldwide epidemiological evidence. Lancet 2019; 394: 1159-1168. [CrossRef]

7. Wang SM, Pfeiffer RM, Gierach GL, Falk RT. Use of postmenopausal hormone therapies and risk of histology- and hormone receptor-defined breast cancer: results from a 15-year prospective analysis of NIHAARP cohort. Breast Cancer Res 2020; 22: 129. (PMID: 33239054) [CrossRef]

8. Rossouw JE, Anderson GL, Prentice RL, LaCroix AZ, Kooperberg C, Stefanick ML, et al. Risks and benefits of estrogen plus progestin in healthy postmenopausal women: principal results from the Women's Health Initiative randomized controlled trial JAMA 2002; 288: 321-333. (PMID: 12117397) [CrossRef] 
9. Glaser R, Kalantaridou S, Dimitrakakis C. Testosterone Implants in women: pharmacological dosing for a physiological effect. Maturitas 2013; 74:179- 184. (PMID: 23265303) [CrossRef]

10. Lambrinoudaki I. Menopausal hormone therapy and breast cancer risk: all progestogens are not the same. Case Rep Womens Health 2021; 29: e00270. doi: 10.1016/j.crwh.2020.e00270 (PMID: 33294389) [CrossRef]

11. Henderson BE, Feigelson HS. Hormonal carcinogenesis. Carcinogenesis 2000; 21: 427-433. (PMID: 10688862) [CrossRef]

12. Ando S, De Amicis F, Rago V, Carpino A, Maggiolini M, Panno ML, et al. Breast cancer: from estrogen to androgen receptor. Mol Cell Endocrinol 2002; 193: 121-128. (PMID: 12161011) [CrossRef]

13. Hofling M, Hirschberg AL, Skoog L, Tani E, Hagerstrom T, vonSchoultz B. Testosterone inhibits estrogen/progestogen-induced breast cell proliferation in postmenopausal women. Menopause 2007; 14: 183-190. (PMID: 17108847) [CrossRef]

14. Dimitrakakis C, Zhou J, Wang J, Belanger A, LaBrie F, Cheng C, et al. A physiologic role for testosterone in limiting estrogenic stimulation of the breast. Menopause 2003; 10: 292-298. (PMID: 17108847) [CrossRef]

15. Dimitrakakis C. Androgens and breast cancer in men and women. Endocrinol Metab Clin North Am 2011; 40: 533-547. (PMID: 21889719) [CrossRef]

16. Cancer Stat Facts: Female Breast Cancer. Surveillance, Epidemiology, and End Results (SEER) Program, National Cancer Institute. Available at: www.seer.cancer.gov/statfacts/html/breast.html

17. Glaser R, York AE, Dimitrakakis C. Beneficial effects of testosterone therapy in women measured by the validated menopause rating scale (MRS). Maturitas. 2011; 68: 355-361. (PMID: 21177051) [CrossRef]

18. Beral V, Reeves G, Bull D, Green J, Million Women Study Collaborators. Breast cancer risk in relation to the interval between menopause and starting hormone therapy. J Natl Cancer Inst 2011; 103: 296-305. (PMID: 21278356) [CrossRef]

19. Greenblatt RB, Suran RR. Indications for hormonal pellets in the therapy of endocrine and gynetic disorders. Am J Obstet Gynecol 1949; 57: 294 301. (PMID: 18123090) [CrossRef]

20. Traish AM, Freeley RL, Guay AT. Testosterone therapy in women with gynecologic and sexual disorders: a triumph of clinical endocrinology from 1938 to 2008. J Sex Med 2009; 63: 334-351. (PMID: 19138368) [CrossRef]

21. Glaser R, Dimitrakakis C. Rapid response to breast cancer to neoadjuvant intramammary testosterone-anastrozole therapy: neoadjuvant hormone therapy in breast cancer. Menopause 2014; 21: 673-678. (PMID: 24149917) [CrossRef]

22. Donovitz G, Schwartz E, Miller C, Barber M, Comite F, Janson K, et al. Testosterone Insufficiency and Treatment in Women: International Expert Consensus 2019. MSP Medicina Y Salud Publica Published: 4 September 2019. [CrossRef]

23. Davison SL, Bell R, Donath S, Montalto JG, Davis SR. Androgen levels in adult females: changes with age, menopause, and oophorectomy. J Clin Endocrinol Metab 2005; 90: 3847-3853. (PMID: 15827095) [CrossRef]

24. Glaser R, Dimitrakakis C. Testosterone and breast cancer prevention. Maturitas 2015; 82: 291-295. (PMID: 26160683) [CrossRef]

25. Colditz GA, Hankinson SE, Hunter DJ, Willett WC, Manson JE, Stampfer MJ, et al. The use of estrogens and progestins and the risk of breast cancer in postmenopausal women. New Engl J Med 1999; 332 : 1589-1593. (PMID: 7753136) [CrossRef]

26. Bachmann G. Female androgen insufficiency: the Princeton consensus statement on definition, classification, and assessment. Fertil Steril 2002; 77: 660-665. (PMID: 11937111) [CrossRef]

27. Handelsman DJ, Conway AJ, Boylan LM. Pharmacokinetics and pharmacodynamics of testosterone pellets in man. J Clin Endocrinol Metab 1990; 71: 216-222. (PMID: 2115044) [CrossRef]

28. Bluming A, Tavris C. Estrogen matters. New York: Little Brown Spark; 2018. [CrossRef]

29. Manson JE, Aragaki AK, Anderson GL,Prentice RL LaCroix AZ, et al, Menopausal hormone therapy and long-term all-cause and cause-specific mortality: the women's health initiative randomized trials. JAMA 2017; 318: 927-938. (PMID: 28898378) [CrossRef]

30. Beex L, Pieters PG, Smals A, Koenders A, Benraad T, Kloppenborg P. Tamoxifen versus ethInyl estradiol in the treatment of post-menopausal women with advanced breast cancer. Cancer Treat Rep 1981; 65: 179185. (PMID: 7237448) [CrossRef]

31. Singhal H, Greene ME, Tarulli G, Zarnke AL, Bourgo RJ, Laine M, et al. Genomic agonism and phenotypic antagonism between estrogen and progesterone receptors in breast cancer. Sci Adv 2016; 2: e1501924. doi: 10.1126/sciadv.1501924. (PMID: 27386569) [CrossRef]

32. Franceschini G, Lello S, Di Leone A, Orlandi A, Masetti R. Menopausal hormone therapy: what should be kept in mind for a personalized choice in a shared decision-making. Eur J Obstet Gynecol Reprod Biol 2020; 246: 191-192. (PMID: 31839443) [CrossRef] 